\title{
Duck enteritis virus infection suppresses viability and induces apoptosis and endoplasmic reticulum stress in duck embryo fibroblast cells via the regulation of $\mathrm{Ca}^{2+}$
}

\author{
Yangzi ZHANG ${ }^{1,2)}$, Xuan WANG ${ }^{2}$, Andong HU ${ }^{1,3)}$, Yutong WU ${ }^{2)}$, Piao ZHANG ${ }^{1,3)}$, \\ Xia YANG ${ }^{1,3)}$, Zhengchang WEN ${ }^{2) *}$ and Ming WEN ${ }^{1,3) *}$ \\ ${ }^{1)}$ College of Animal Science, Guizhou University, Guiyang 550025, PR China \\ 2)Institute of Animal Husbandry and Veterinary Medicine of Guizhou Academy of Agricultural Sciences, \\ Guiyang 550005, PR China \\ 3)Institute of Animal Epidemics, Guizhou University, Guiyang 550025, PR China
}

\begin{abstract}
Duck viral enteritis (DVE) is a lethal viral disease caused by duck enteritis virus (DEV) via an unknown mechanism. This study explores the relationship between Chinese standard challenge strain DEV (DEV-CSC)-induced apoptosis and endoplasmic reticulum stress (ERS) in duck embryo fibroblast (DEF) cells. Here we examined changes in $\mathrm{Ca}^{2+}$ concentration, cell proliferation, apoptosis, and the differential expression of C/EBP homologous protein (CHOP), glucose regulatory protein 78 (GRP78), and activating transcription factor 6 (ATF6) in infected cells. The results revealed that DEV-CSC infection significantly decreased $\mathrm{Ca}^{2+}$ concentration, suppressed cell viability, and induced apoptosis in DEF cells. Further experiments also demonstrated that DEVCSC infection significantly upregulates CHOP, GRP78, and ATF6 expression. In addition, we show that the addition of ethylenediaminetetraacetic acid (EDTA) reverses the induction of apoptosis and the ERS mediated inhibition of cell viability in DEF cells associated with DEV-CSC infection. Therefore, we can conclude that infection with DEV-CSC induces apoptosis and ERS reducing the viability of DEF cells via the regulation of $\mathrm{Ca}^{2+}$. These findings may provide a new target for the treatment of DVE.

KEY WORDS: apoptosis, duck enteritis virus, endoplasmic reticulum stress, ethylenediaminetetraacetic acid
\end{abstract}

J. Vet. Med. Sci.

83(3): 549-557, 2021

doi: $10.1292 / j v m s .19-0584$

Received: 26 October 2019

Accepted: 24 September 2020 Advanced Epub:

28 October 2020

Duck viral enteritis (DVE), also called duck plague, is caused by infection with Anatid alphaherpesvirus-1 or DVE virus (DVEV), a member of the Alphaherpesvirinae subfamily of Herpesviridae, genus Mardivirus. DVE is a novel lethal viral disease transmitted in ducks, geese, swans, and several other anseriformes birds [27]. Infection with duck enteritis virus (DEV) causes the characteristic vascular damage, gastrointestinal mucosal erosion, lymphoid organ injury, and substantial organ degeneration associated with DVE and can result in high mortality rates and significant economic losses in the duck industry [33, 34]. At present, studies on DEV have primarily focused on its epidemiology and genetic structure and modification. However, the pathogenic mechanism underlying DEV infections has been poorly reported.

The endoplasmic reticulum (ER) is an important calcium reservoir in cells [6]. It regulates protein synthesis by maintaining the $\mathrm{Ca}^{2+}$ balance necessary for homeostasis in the cytoplasm and the cellular membranes [3]. In addition, $\mathrm{Ca}^{2+}$ acts as an important second messenger molecule in the cells and participates in various physiological activities including cellular proliferation, differentiation, exercise, muscle contraction, hormone secretion, glycogen metabolism and neuronal signaling thus regulating cell secretion, metabolism, and apoptosis [4, 37]. Endoplasmic reticulum stress (ERS) is a protective stress response described in most eukaryotic cells [22]. During ERS, some of the proteins synthesized in the ER are either not folded or misfolded [25], disrupting the protein balance in the cells, reducing protein production and resulting in functional perturbations. These non-functional proteins will gradually accumulate in the ER forcing the cells to activate constant ERS and the unfolded protein response (UPR) [5]. UPR signals are regulated via three signal proteins, RNA-dependent protein kinase-like endoplasmic kinase (PERK), inositol-requiring enzyme (IRE), and activating transcription factor (ATF) [18, 21]. However, long-term ERS/UPR is not feasible because the UPR

*Correspondence to: Wen, Z.: 911135914@qq.com, Wen, M.: as.mwen@gzu.edu.cn (Supplementary material: refer to PMC https://www.ncbi.nlm.nih.gov/pmc/journals/2350/)

O2021 The Japanese Society of Veterinary Science

This is an open-access article distributed under the terms of the Creative Commons Attribution Non-Commercial No Derivatives (by-nc-nd) License. (CC-BY-NC-ND 4.0: https://creativecommons.org/licenses/by-nc-nd/4.o/) 
load becomes too large to maintain the protein balance of the whole cell and the expression of C/EBP homologous protein (CHOP) is activated in response inducing the cell to enter apoptosis [7].

Glucose regulatory protein 78 (GRP78), is a trigger protein regulating the expression of UPR signaling pathways, and is upregulated during ERS/UPR. Cells infected with foreign viruses often experience changes in their protein balance [10]. Dengue and West Nile virus (WNV) have been found to induce ERS through an increase in GRP78 expression [1, 34]. These viruses can regulate the expression of GRP78, thereby regulating one or more UPR signaling pathways. Annelies et al. [26] found that UPR is started almost immediately following the onset of ERS in cells infected with Hepatitis B Virus (HBV) or Hepatitis C Virus (HCV), and that this process also regulates HBV or HCV replication. Recent studies reported [17, 23] that CHOP may be involved in apoptosis induced by ERS, particularly, in promoting the transformation of viral hepatitis to liver cancer, with HBsAg expression being positively correlated with GRP78 expression. UPR pathways are associated with the apoptosis and pathogenic mechanisms of several pathogens, including HBV and HCV.

Although few studies $[13,16,28]$ have evaluated the relationship between infection and ERS/UPR viral infections may virustrigger the up-regulation of $\mathrm{Ca}^{2+}$ retention thereby inducing the UPR pathways. Here, we show that Chinese standard challenge strain DEV (DEV-CSC) infection triggers $\mathrm{Ca}^{2+}$ upregulation and UPR. This response included DEV-CSC-induced apoptosis and the upregulation of the UPR signaling pathway, which could be blocked by the addition of ethylenediaminetetraacetic acid (EDTA).

\section{MATERIALS AND METHODS}

\section{Cell culture and DEV-CSC infection}

As previously described [19], DEF cells from pathogen-free duck embryos of between 9 and 11-days of age were incubated in Dulbecco's modified Eagle's medium (DMEM; Hyclone, Life Technologies, Carlsbad, CA, USA) supplemented with 10\% fetal bovine serum (FBS; Gibco, Grand Island, NY, USA) and $0.1 \mathrm{mg} / \mathrm{ml}$ streptomycin and $0.1 \mathrm{mg} / \mathrm{ml}$ penicillin. The use of duck embryos was also approved by the Animal Ethics Committee of Guizhou University (approval no. 19010125). DEV-CSC was provided by the Chinese Institute of Veterinary Drug Control. DEV-CSC at different multiplicities of infection (MOI) were applied to DEF cells and incubated at $37^{\circ} \mathrm{C}$ for $2 \mathrm{hr}$ [35]. After the viral suspension was removed, the cells were washed with sterile phosphate-buffered saline (PBS; Sigma-Aldrich, St. Louis, MO, USA, cat. no. P2194) three times and maintained in medium with $2 \%$ FBS. Ten mM Ethylene diamine tetraacetic acid (EDTA) (3-MA; Sigma-Aldrich) or 0, $50 \mu \mathrm{M}$, and $100 \mu \mathrm{M}$ EDTA Acetoxymethyl ester (EDTA-AM; Sigma-Aldrich) were added to the medium $2 \mathrm{hr}$ prior to DEV-CSC infection as the Ca ${ }^{2+}$ chelator.

\section{Cell viability assays}

As directed by the instrument manufacturer DEF cell viability after DEV-CSC infection was evaluated using a cell counting kit-8 (CCK-8; Beyotime Biotechnology, Shanghai, China). Briefly, $5 \times 10^{4}$ cells were seeded into 96-well plates and infected with $0,0.1,1$, or 10 MOI DEV-CSC. After 0,2 , and $4 \mathrm{hr}$, the DEV-CSC was removed, and the cells were cultured in normal medium. After $48 \mathrm{hr}$, the CCK-8 solution was added to the medium and incubated for $1 \mathrm{hr}$, and absorbance was determined at $450 \mathrm{~nm}$. The greater the cell viability, the higher the absorbance. To identify the best time point for downstream experiments cell viability was evaluated at $0,24,48$, and $72 \mathrm{hr}$ after $10 \mathrm{MO} 1 \mathrm{DEV}-\mathrm{CSC}$ infection using CCK8.

\section{Apoptosis assays}

DEV-CSC-induced DEF apoptosis was analyzed using flow cytometry. The rate of apoptosis was further determined using an annexin V-FITC apoptosis detection kit (Solarbio, Beijing, China, cat. no. CA1020). Briefly, $1 \times 10^{6}$ cells were harvested and washed with cold PBS and then resuspended in $1 \mathrm{ml}$ of $1 \times$ binding buffer. After incubation with annexin V-FITC and PI, the apoptotic cells were detected by flow cytometry within $1 \mathrm{hr}$. The upper left (UL) quadrant ((AnnexinV-FITC) $\left.{ }^{-} / \mathrm{PI}^{+}\right)$denotes necrosis, the upper right quadrant $\left.(\text { AnnexinV }+\mathrm{FITC})^{+} / \mathrm{PI}^{+}\right)$denotes late apoptosis, the lower right (LR) quadrant $((\mathrm{AnnexinV}-$ FITC $\left.)^{+} / \mathrm{PI}^{-}\right)$denotes early apoptosis and the lower left (LL) quadrant ((AnnexinV-FITC $\left.)^{-} / \mathrm{PI}^{-}\right)$denotes viable cells. Total apoptosis was equal to the sum of the late and early apoptosis values.

\section{Western blot}

Following DEV-CSC infection DEF cells were treated with radioimmunoprecipitation assay buffer (RIPA, Beyotime, China) containing phenylmethylsulfonyl fluoride (PMSF) at a ratio of 100 to 1 on ice. After 20 min of centrifugation, the total proteins were harvested and quantitatively analyzed using bicinchoninic acid (Beyotime Institute of Biotechnology, Nanjing, China). Each well of a $10 \%$ sodium dodecyl sulfate-polyacrylamide gel electrophoresis (SDS-PAGE) gel were loaded with $50 \mu \mathrm{g}$ of total protein, electrophoresed and then transferred to polyvinylidene difluoride membranes (PVDF; Millipore, Billerica, MA, USA). After blocking with $5 \%(\mathrm{w} / \mathrm{v})$ nonfat milk, the proteins were incubated with primary antibodies at $4^{\circ} \mathrm{C}$ overnight. The next day, the proteins were labeled with a secondary antibody for $1 \mathrm{hr}$ and the chemical signals were evaluated using the enhanced chemiluminescence detection kit (Beyotime) on the Tanon-5500 imaging system. The quantitative data were analyzed using Image J software. The primary antibodies used were as follows: CHOP (1:250; Abcam, Cambridge, UK, ab10444), GRP78 (1 $\mu \mathrm{g} / \mathrm{ml}$; Abcam, ab21685), ATF6 (1:300; Abcam, ab135707), and GAPDH (0.5 $\mu \mathrm{g} / \mathrm{ml}$; Abcam, ab37168). The secondary antibody was goat anti-mouse IgG H\&L (1:1,000; Abcam, ab97040). 
A

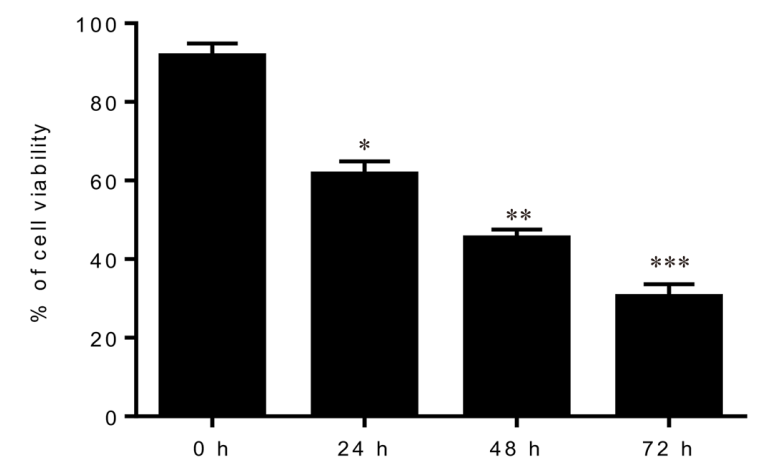

C

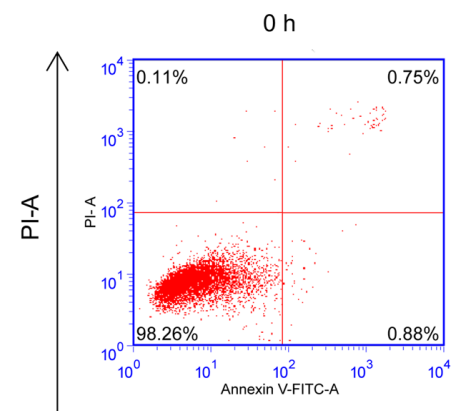

B

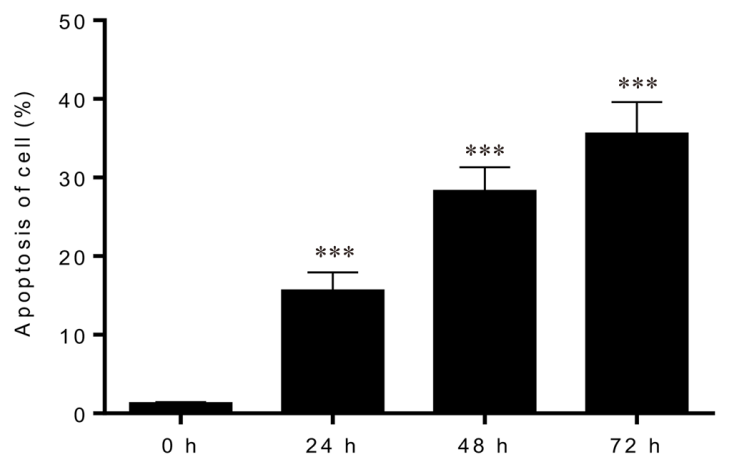

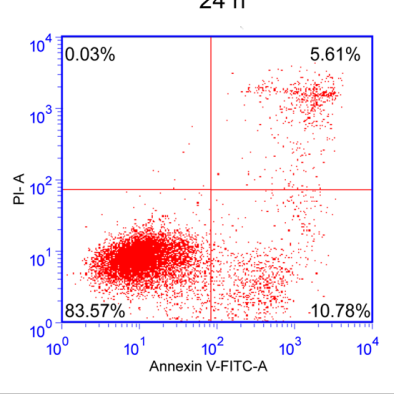
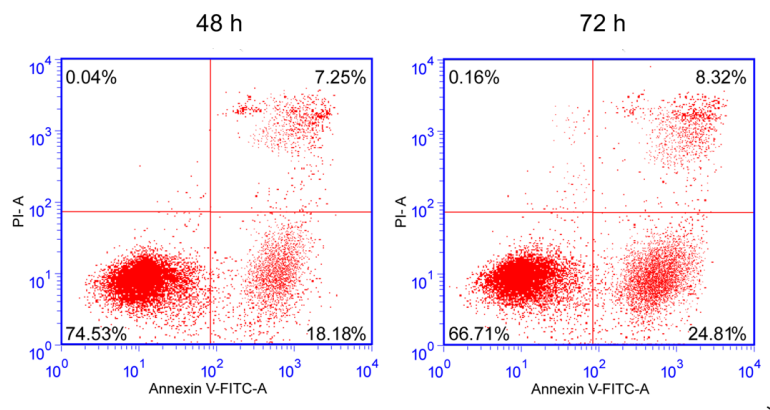

Annexin V-FITC-A

Fig. 1. Chinese standard challenge strain duck enteritis virus (DEV-CSC) infection induced apoptosis and inhibited viability in a time dependent manner. Duck embryo fibroblast (DEF) cells were infected with 10 multiplicity of infection (MOI) DEV-CSC for $2 \mathrm{hr}$, and cultured in normal medium for $0 \mathrm{hr}, 24 \mathrm{hr}, 48 \mathrm{hr}$ and $72 \mathrm{hr}$. (A) The cell viability was assessed by cell counting kit 8 (CCK8) assay. (B-C) Cell apoptosis was estimated using flow cytometry and an annexin V fluorescein isothiocyanate (annexin V-FITC) apoptosis detection kit. Values are expressed as the mean $\pm \mathrm{SD}(\mathrm{n}=3) . *: P<0.05, * *: P<0.01, * * *: P<0.001$ vs. the $0 \mathrm{hr}$ group.

\section{Measurement of intracellular $\mathrm{Ca}^{2+}$}

Intracellular $\mathrm{Ca}^{2+}$ concentration was evaluated using $4 \mu \mathrm{M}$ Fluo-4 AM (Bridgen, China). Fluo-4 AM was added to DEF cells and allowed to react for $1 \mathrm{hr}$ at $37^{\circ} \mathrm{C}$ in the dark according to the manufacturer's specifications. Then, the cells were washed with HEPES buffered saline three times and adjusted to a concentration of $1 \times 10^{5}$ cells $/ \mathrm{ml}$. $\mathrm{Ca}^{2+}$ concentration was evaluated using a fluorescence microscope at $488 \mathrm{~nm}$.

\section{Statistical analysis}

Each experiment was conducted in triplicate, and all experimental values were recorded as the mean \pm standard deviation (SD). Statistical analysis was performed using SPSS 12.0 software and the Student's $t$ test. A $P$ value of $<0.05$ was considered statistically significant.

\section{RESULTS}

\section{$D E V$-CSC infection induced apoptosis and inhibited viability in a time dependent manner}

To determine the impact of DEV-CSC infection on DEF cells, DEF cells were infected with 10 MOI DEV-CSC and cultured for 0, 24, 48, and $72 \mathrm{hr}$. DEF cells were infected with 10 MOI DEV-CSC, and the cell viability was evaluated at different time points. As shown in Fig. 1A, cell viability decreased in a time-dependent manner, with the highest loss of viability (50\%) at $48 \mathrm{hr}$ after DEBV CSC infection. Cytotoxicity evaluations showed that DEV-CSC also induced DEFs apoptosis in a time-dependent manner (Fig. 1B).

\section{$D E V-C S C$ infection induced apoptosis and $\mathrm{Ca}^{2+}$ accumulation inhibiting DEF cell viability}

To further investigate the optimal time and concentration of DEV-CSC infection, DEF cells were infected with different amounts of DEV-CSC for different time periods. First, the results revealed that the viability of DEF cells was significantly reduced at 2 $\mathrm{hr}$ and $4 \mathrm{hr}$ after $10 \mathrm{MOI}$ DEV-CSC infection compared with the control group, with the most significant difference at $4 \mathrm{hr}$ after infection $(P<0.05, P<0.01$, Fig. 2A). Second, flow cytometry revealed that apoptosis in the DEF cells was dramatically elevated 
A

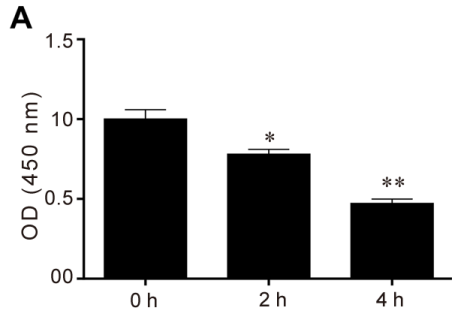

D

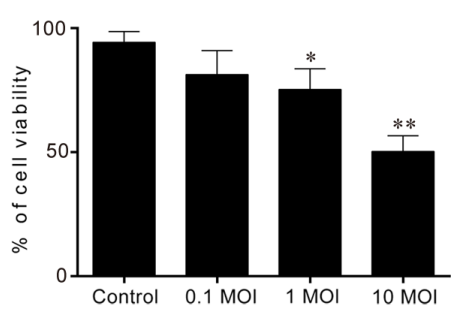

F

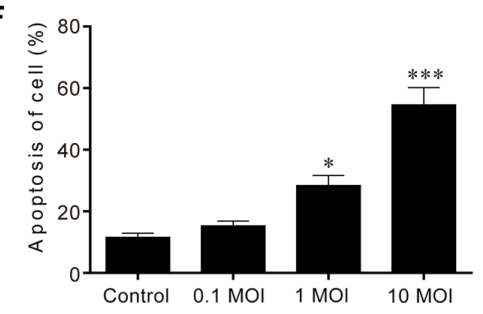

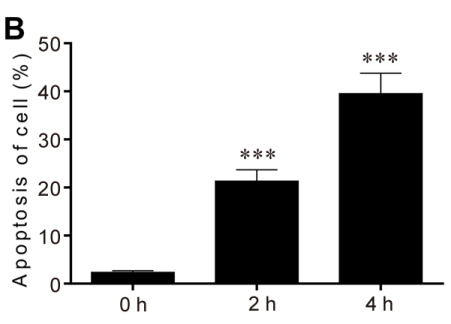

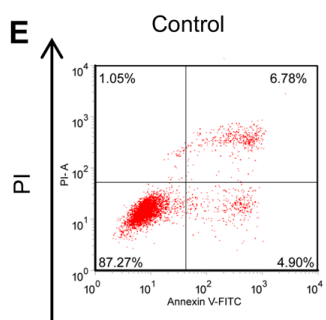

G

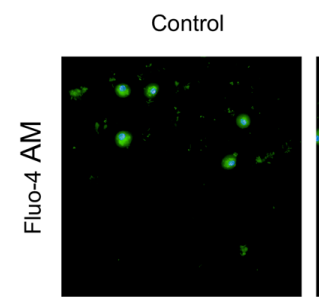

C
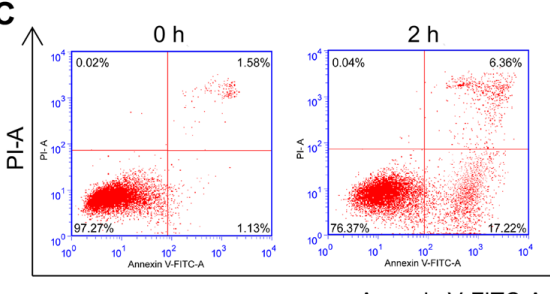

Annexin V-FITC-A

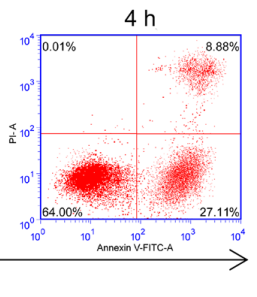

$0.1 \mathrm{MOI}$
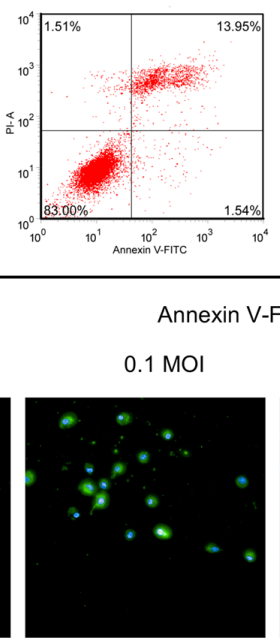

$1 \mathrm{MOI}$

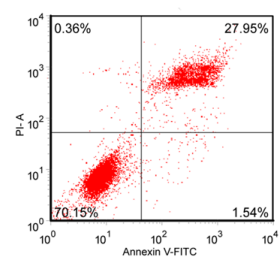

$1 \mathrm{MOI}$

$10 \mathrm{MOI}$

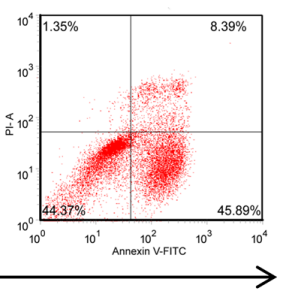

$10 \mathrm{MOI}$
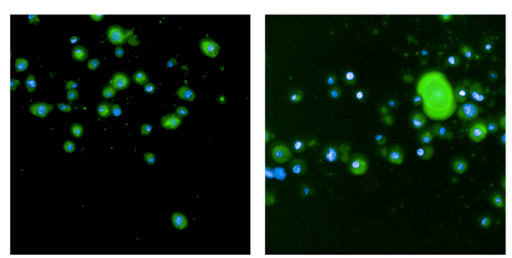

Fig. 2. Chinese standard challenge strain duck enteritis virus (DEV-CSC) infection induced apoptosis and $\mathrm{Ca}^{2+}$ accumulation inhibiting duck embryo fibroblast (DEF) cell viability. (A) Cell counting kit 8 (CCK-8) assay was used to determine the viability of DEF cells infected with 10 multiplicity of infection (MOI) DEV-CSC for 0,2 and $4 \mathrm{hr}$, respectively, and then cultured in normal medium for $48 \mathrm{hr}$. (B-C) After treatment with 10 MOI DEV-CSC for 0,2 and $4 \mathrm{hr}$, flow cytometry was used to evaluate apoptosis in DEF cells after culture in normal medium for 48 hr. (D) The cell viability was confirmed at $48 \mathrm{hr}$ after infection with DEV-CSC at doses of 0-10 MOI. (E-F) Cell apoptosis was examined using flow cytometry and $(\mathrm{G}) \mathrm{Ca}^{2+}$ mediated cellular fluorescence was analyzed using Fluo-4. Values are expressed as the mean $\pm \mathrm{SD}(\mathrm{n}=3$ ). $*: P<0.05, * *: P<0.01, * * *: P<0.001$ vs. the control.

at $2 \mathrm{hr}$ and $4 \mathrm{hr}$ after $10 \mathrm{MOI}$ DEV-CSC infection relative to the control, especially at the $4 \mathrm{hr}$ after infection time point $(P<0.01$, Fig. $2 \mathrm{~B}$ and $2 \mathrm{C}$ ). Therefore, we proposed that " $2 \mathrm{hr}$ " was the most suitable incubation period for DEV-CSC infection in the analysis of DEF cells. Then cell viability was examined at $48 \mathrm{hr}$ after different MOIs of DEV-CSC were used in $2 \mathrm{hr}$ infections. Cell viability was decreased in a virus dose-dependent manner (Fig. 1D) which was most easily evaluated in the 10 MOI DEV-CSC group where the viability of the DEF cells decreased by approximately $50 \%(P<0.05, P<0.01)$. Flow cytometry analysis showed that the apoptosis rates of the DEF cells were $11.7 \%, 15.5 \%, 29.5 \%$, and $58.4 \%$ after infection with DEV-CSC at doses of $0,0.1,1$, and 10 MOI, respectively $(P<0.05, P<0.001$, Fig. $1 \mathrm{E}$ and $1 \mathrm{~F})$. Subsequently, intracellular $\mathrm{Ca}^{2+}$ was evaluated and the results are summarized in Fig 1G. Fluorescence intensity was positively correlated with infection dose. Taken together these results indicate that DEV-CSC decreases cell viability and induces apoptosis in a dose and time dependent manner in DEFs.

\section{DEV-CSC induced ERS/UPR in DEF cells}

We then went on to investigate the influence of DEV-CSC infection on the expression of ERS-related proteins (GRP78, ATF6, and CHOP). First, we confirmed the antibody reactions against avian (duck) antigens using western blot (Supplementary Fig. 1). This confirmation means that the primary antibodies against GRP78, ATF6, and CHOP can react with the duck antigens produced by the DEF cells used in this study. Next, we infected DEF cells with different doses of DEV-CSC and found that the protein levels of GRP78 and ATF6 were significantly upregulated in the $0.1 \mathrm{MOI}(P<0.05), 1 \mathrm{MOI}(P<0.001)$, and $10 \mathrm{MOI}(P<0.001)$ groups, and that the protein expression of CHOP was steadily upregulated until the DEV-CSC concentration reached $1 \mathrm{MOI}(P<0.001)$ or $10 \mathrm{MOI}(P<0.001)$ when compared to the 0 MOI group. These results suggest that DEV-CSC induced ERS/UPR in DEF cells upregulates the expression of CHOP, but despite UPR induction the lower doses were not sufficient to induce apoptosis (Fig. 3).

\section{DEV-CSC induced apoptosis of DEF cells by $\mathrm{Ca}^{2+}$ transport}

DEF cells infected with 10 MOI DEV-CSC exhibited a higher cytosolic $\mathrm{Ca}^{2+}$ concentration than cells without DEV-CSC infection, illustrating that DEV-CSC disturbed the balance of $\mathrm{Ca}^{2+}$ homeostasis in these cells (Fig. 4A). The addition of EDTA successfully inhibited this increased $\mathrm{Ca}^{2+}$ influx increasing the viability of DEF cells $(P<0.05$, Fig. $4 \mathrm{~B})$. In addition, flow cytometry 

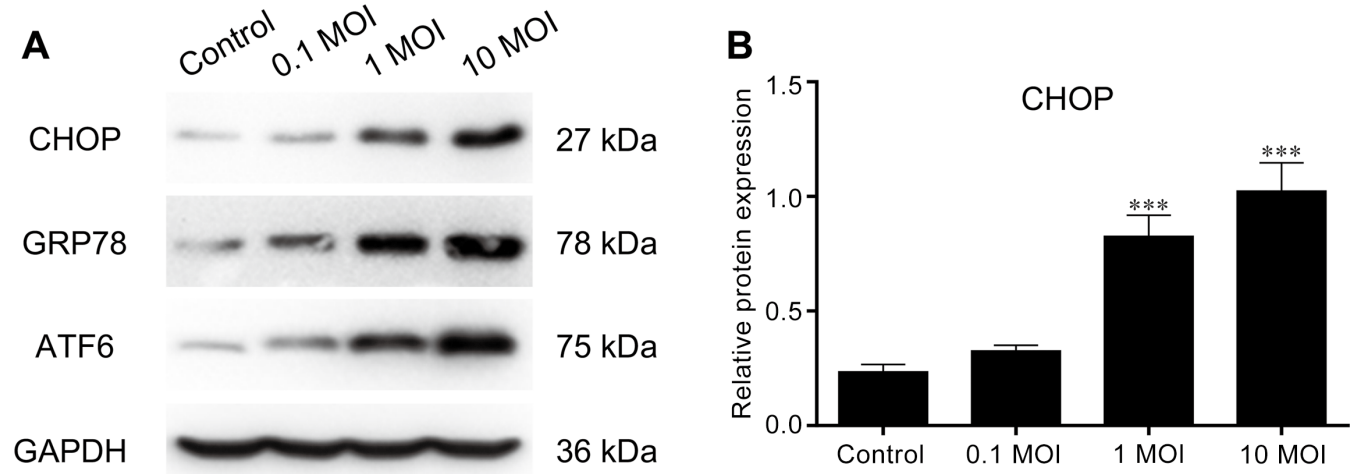

C

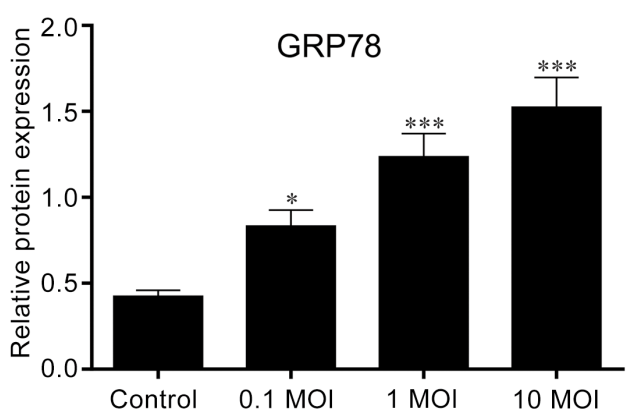

D

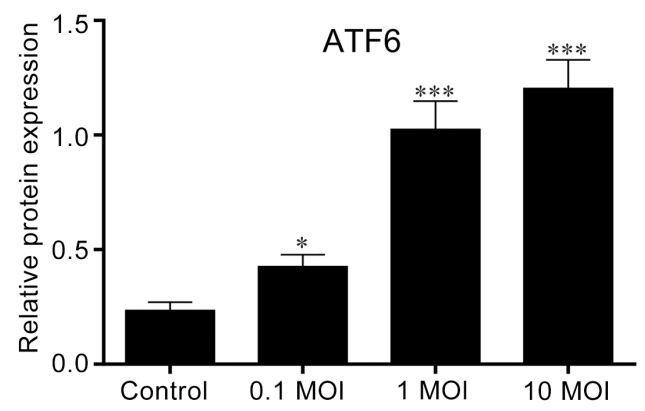

Fig. 3. Different doses of Chinese standard challenge strain duck enteritis virus (DEV-CSC) induced unfolded protein response (UPR) in duck embryo fibroblast (DEF) cells. DEF cells were infected with 0-10 multiplicity of infection (MOI) DEV-CSC for $2 \mathrm{hr}$, and then cultured in normal medium for $48 \mathrm{hr}$. (A) Western blot was then used to evaluate the protein expression levels of C/EBP homologous protein (CHOP), glucose regulatory protein 78 (GRP78) and activating transcription factor 6 (ATF6) after 0-10 MOI DEV-CSC infection. The relative expression levels of CHOP (B), GRP78 (C) and ATF6 (D) were quantified based on their gray values. *: $P<0.05$, ***: $P<0.001$ vs. the control group.

A

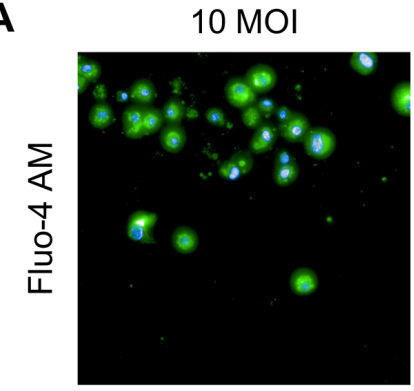

C

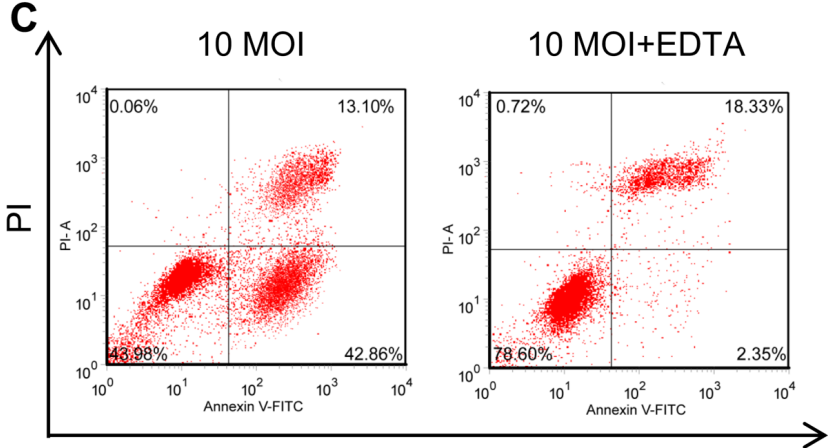

$10 \mathrm{MOI+EDTA}$

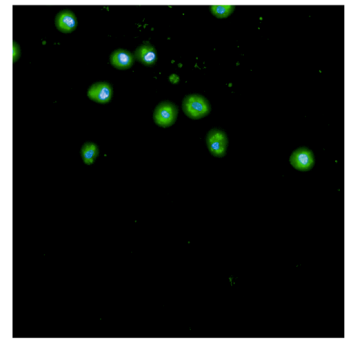

D
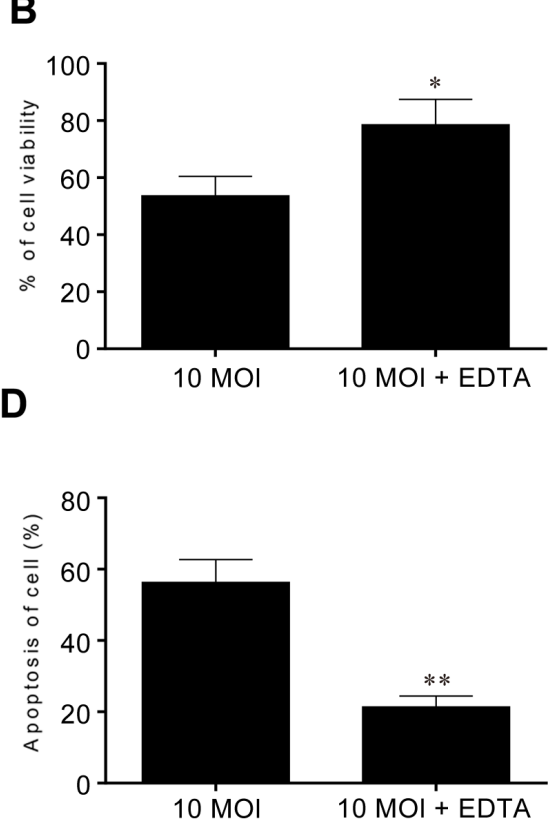

Annexin V-FITC

Fig. 4. Chinese standard challenge strain duck enteritis virus (DEV-CSC) induces apoptosis in duck embryo fibroblast (DEF) cells via changes in $\mathrm{Ca}^{2+}$. DEF cells were infected with 10 multiplicity of infection (MOI) DEV-CSC for $2 \mathrm{hr}$, and then cultured in normal medium supplemented with ethylene diamine tetraacetic acid (EDTA) for $48 \mathrm{hr}$. (A) The $\mathrm{Ca}^{2+}$ fluorescence of EDTA chelated DEF cells was evaluated using Fluo-4 while (B) cell viability was evaluated using the CCK-8 assay in DEF cells treated with 10 MOI or 10 MOI+EDTA; (C-D) Apoptosis in DEF cells treated with $10 \mathrm{MOI}$ or $10 \mathrm{MOI}+\mathrm{EDTA}$ was also evaluated using flow cytometry. *: $P<0.05$, **: $P<0.01$, vs. the 10 MOI group. 


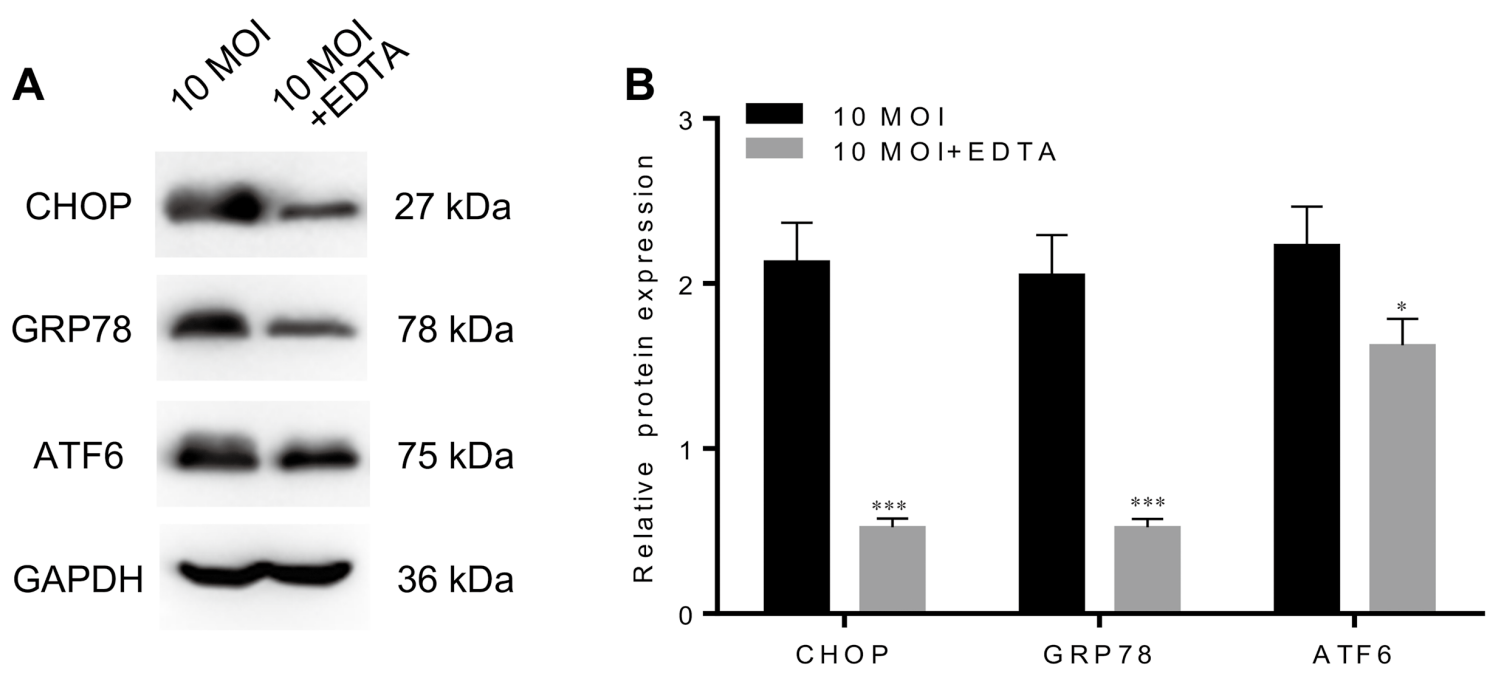

Fig. 5. Chinese standard challenge strain duck enteritis virus (DEV-CSC) induced endoplureasmic reticulum stress (ERS) in duck embryo fibroblast (DEF) cells via the regulation of $\mathrm{Ca}^{2+}$. DEF cells were infected with 10 multiplicity of infection (MOI) DEV-CSC for $2 \mathrm{hr}$, and then treated with ethylene diamine tetraacetic acid (EDTA) for $48 \mathrm{hr}$. (A) Western blot analysis of C/EBP homologous protein (CHOP), glucose regulatory protein 78 (GRP78) and activating transcription factor 6 (ATF6) expression in $10 \mathrm{MOI}$ infected DEF cells with/without EDTA-treatment. (B) Relative expression of CHOP, GRP78 and ATF6 were quantified using their gray values. *: $P<0.05, * * *: P<0.001$ vs. the 10 MOI group.

also showed that the apoptosis rate was significantly decreased after treatment with EDTA compared with the positive control $(P<0.01$, Fig. 4C and 4D). Taken together, these results suggest that DEV-CSC-induced apoptosis in DEF cells is closely associated with autophagy mediated by $\mathrm{Ca}^{2+}$ influx.

\section{DEV-CSC induced ERS/UPR in DEF cells is regulated by $\mathrm{Ca}^{2+}$ transport}

Here, DEF cells were infected with 10 MOI DEV-CSC and the experimental groups were treated with EDTA according to the description in the materials section. The expression levels of CHOP, GRP78, and ATF6 were then evaluated by western blot and the results show that the expression of CHOP $(P<0.001)$, GRP78 $(P<0.001)$, and ATF6 $(P<0.05)$ were all significantly downregulated compared to (Fig. 5). Therefore, we suggest that $\mathrm{Ca}^{2+}$ is chelated by EDTA downregulating the expression of the UPR pathways.

\section{DEV-CSC suppressed viability, induced apoptosis and ERS/UPR in DEF cells via the regulation of $\mathrm{Ca}^{2+}$}

In addition, different concentrations of EDTA, a calcium chelator, were added to verify these results. EDTA treatment abolished the inhibition of cell viability and enhanced apoptosis caused by DEV-CSC infection (Fig. 6A-C). Moreover, the expression of CHOP, GRP78, and ATF6 in DEF cells was also significantly downregulated in response to EDTA (Fig. 6D), further supporting our hypothesis that $\mathrm{Ca}^{2+}$ plays an important role in DEV-CSC mediated inhibition of cell viability.

\section{DISCUSSION}

To date researchers have explored the innate immune response to DEV-CSC infection and established a cDNA library from DEF cells after infection with DEV, which are both valuable resources when studying DEV pathogenesis [12, 20]. However, the pathogenic mechanism of DVE has not been effectively resolved. In this study, we discovered that DEV-CSC infection induces ERS/UPR and apoptosis in DEF cells via $\mathrm{Ca}^{2+}$ influx which could provide a foundation for the development of a novel DVE therapy.

ERS/UPR is a highly conserved physiological metabolic pathway, allowing for a balance between growth and protection in eukaryotic cells [36]. In this study, we clarified that when DEF cells were infected with virus it could induce ERS/UPR mediated apoptosis to prevent unrestricted viral replication.

Several reports have shown that $\mathrm{Ca}^{2+}$-dependent apoptosis occurs after infection with various viruses [9] including HCV [2], human T-cell leukemia virus type 1 [30], HIV [14, 15], and Rotavirus [29]. Furthermore, Ueda et al. [32] showed that H5N1-AIV infection causes the inflow of extracellular $\mathrm{Ca}^{2+}$ and apoptosis of DEF. In addition, the findings in our study may be due to cellular $\mathrm{Ca}^{2+}$ cascade regulation. Cells maintain very low $\mathrm{Ca}^{2+}$ levels by actively pumping cellular $\mathrm{Ca}^{2+}$ to the ER, where it can bind to various host molecules [11]. After DEV-CSC infection, $\mathrm{Ca}^{2+}$ homeostasis is disrupted, and apoptosis occurs through multiple apoptotic pathways. To further investigate the roles of $\mathrm{Ca}^{2+}$ and ERS/UPR in DEF cells, multiple experiments were conducted.

ATF6 is a cryptic transcription factor and plays a vital role in the activation of UPR. When the ER luminal domain senses proteotoxity, ATF6 trafficks to the Golgi and undergoes cleavage of its transmembrane domain. After that, ATF6 is released into the cytosol and induces UPR-related cell apoptosis [31]. Another key protein in UPR is CHOP, a pro-apoptosis transcription 
A

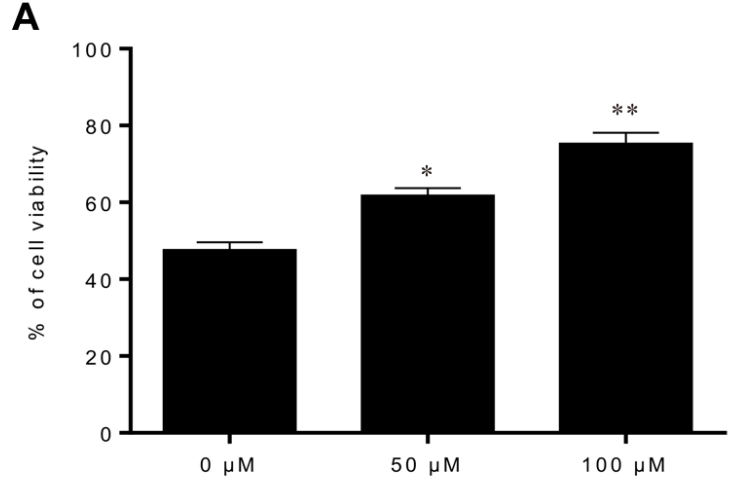

B

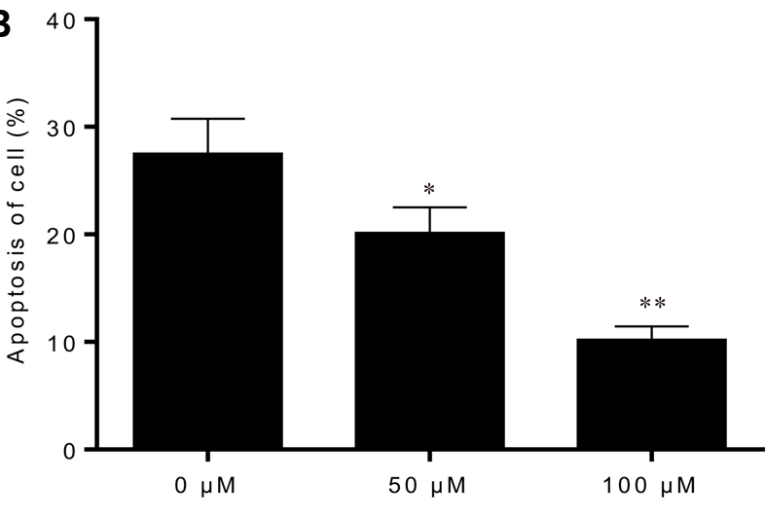

C

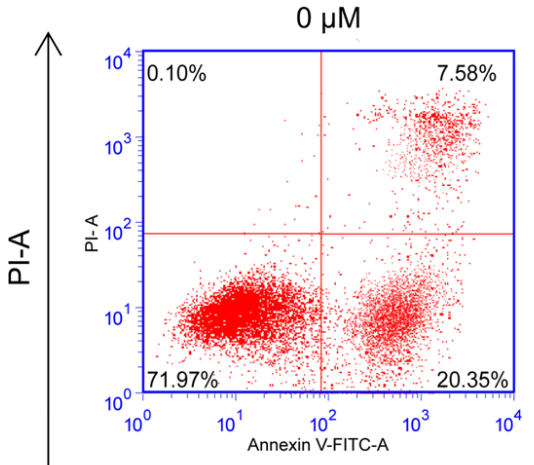

$50 \mu \mathrm{M}$

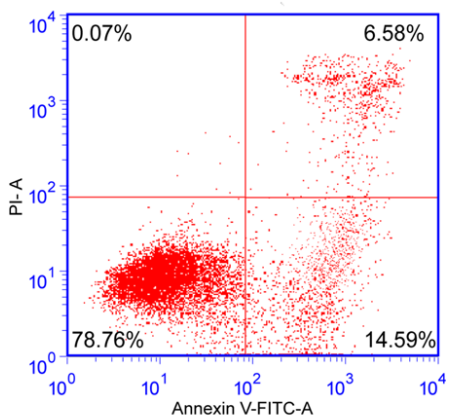

$100 \mu \mathrm{M}$

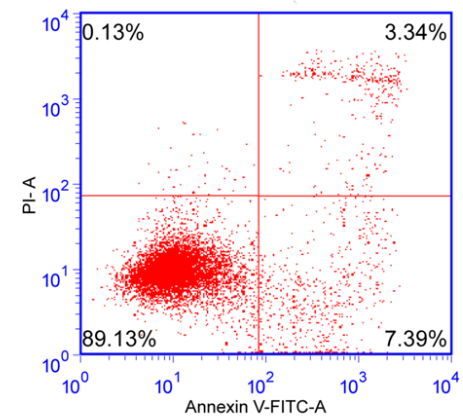

Annexin V-FITC

D
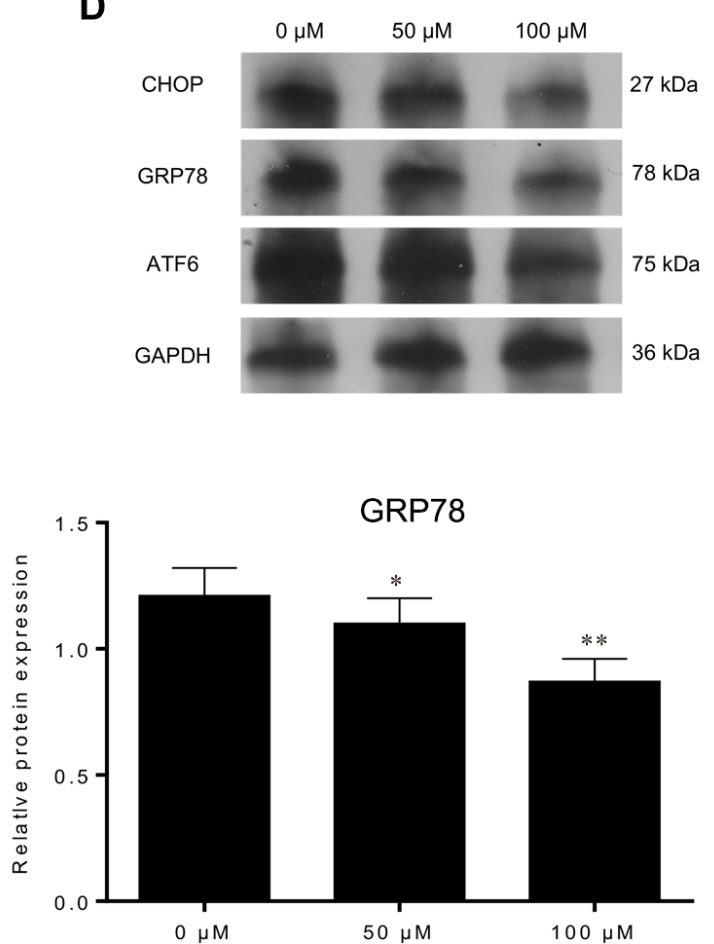

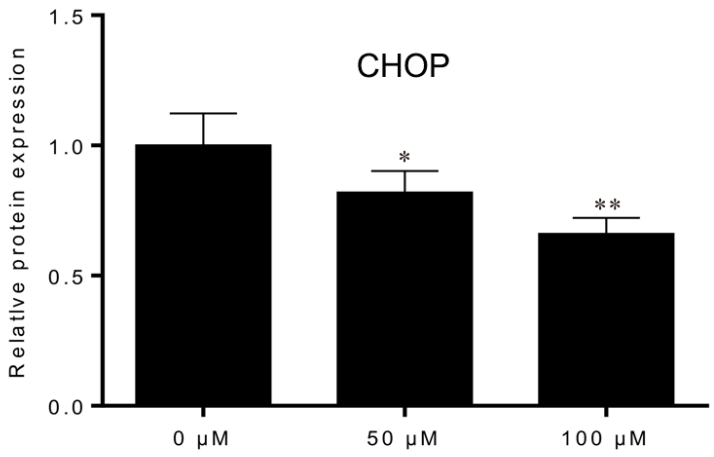

ATF6

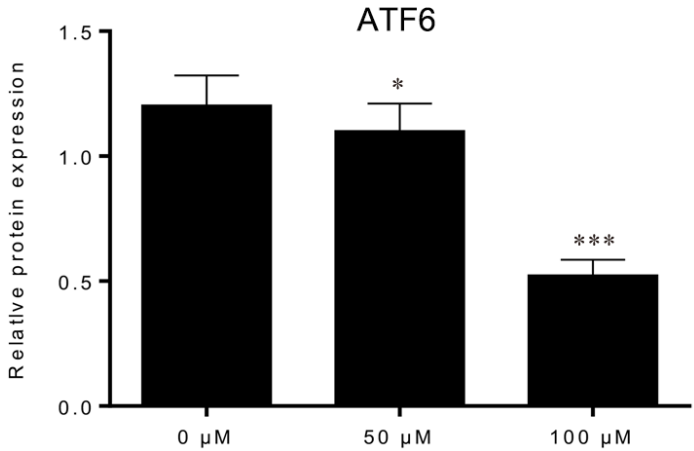

Fig. 6. Chinese standard challenge strain duck enteritis virus (DEV-CSC) suppressed viability and accelerated apoptosis and endoplasmic reticulum stress (ERS) in duck embryo fibroblast (DEF) cells through the regulation of $\mathrm{Ca}^{2+}$. DEF cells were infected with 10 multiplicity of infection (MOI) DEV-CSC for $2 \mathrm{hr}$, and then were cultured with normal medium supplemented with $0 \mu \mathrm{M}, 50 \mu \mathrm{M}$ or $100 \mu \mathrm{M}$ ethylene diamine tetraacetic acid (EDTA) for $48 \mathrm{hr}$. (A) Cell viability was then evaluated using cell counting kit 8 (CCK-8) assay and (B-C) apoptosis was quantified using flow cytometry. (D) After $2 \mathrm{hr}$ of infection with $10 \mathrm{MOI}$ DEV-CSC, DEF cells were treated with $0 \mu \mathrm{M}, 50 \mu \mathrm{M}$ or $100 \mu \mathrm{M}$ EDTA for $48 \mathrm{hr}$. The expression of UPR related proteins were then determined by Western blot. *: $P<0.05, * *: P<0.01, * * *: P<0.001$ vs. the $0 \mu \mathrm{M}$ group. 
factor, which is activated by ATF6 and induces UPR and apoptosis by down-regulating bcl-2 [8]. GRP78 is encoded by the $H s p 5 a$ gene, and its expression is normally maintained at a low level. When cells are under stress, GRP78 is upregulated and promotes the activation of UPR [8]. In our study, ATF6, GRP78, and CHOP were all detected and the expressions of these proteins were all upregulated in response to DEV-CSC infection, illustrating that DEV-CSC infection can regulate UPR signaling pathways in a similar fashion to $\mathrm{Ca}^{2+}$. To explore whether $\mathrm{Ca}^{2+}$ can regulate UPR or not, EDTA was used to chelate $\mathrm{Ca}^{2+}$ in DEF cells. The results showed that cell viability, apoptosis, and the expression of key proteins (CHOP, GRP78, and ATF6) can be reversed by the addition of EDTA in DEV-CSC-infected cells, suggesting that changes in $\mathrm{Ca}^{2+}$ transport is critical for UPR in DEV-CSC infection. In homeostasis, the concentration of $\mathrm{Ca}^{2+}$ in the ER is never higher than that of the cytoplasm and $\mathrm{Ca}^{2+}$ pumps are closely regulated to facilitate the release and uptake of $\mathrm{Ca}^{2+}$ in ES. When the $\mathrm{Ca}^{2+}$ homeostasis is disrupted by DEV infection the cells respond by inducing UPR and apoptosis [24].

In this study, we have shown that high-dose DEV-CSC infections activate apoptosis via $\mathrm{Ca}^{2+}$-mediated ERS/UPR, and that this mechanism may be related to calreticulin. Further studies are needed to evaluate the role of calreticulin in $\mathrm{Ca}^{2+}$ homeostasis and ERS/UPR induction following DEV infection. We also plan to evaluate if other viral strains also affect the apoptosis of DEF cells through $\mathrm{Ca}^{2+}$-mediated ERS/UPR.

POTENTIAL CONFLICTS OF INTEREST. The authors have nothing to disclose.

ACKNOWLEDGMENTS. This study was supported by the National Natural Science Foundation of China (No. 31560703), the Guizhou Province Science and Technology Plan Project (No. QKH[2019]2287; No. QKH[2020]1Y137) and the Grant of Guiyang Comprehensive Test Station of National Waterfowl Industry Technology System (Cars-42-53).

\section{REFERENCES}

1. Ambrose, R. L. and Mackenzie, J. M. 2011. West Nile virus differentially modulates the unfolded protein response to facilitate replication and immune evasion. J. Virol. 85: 2723-2732. [Medline] [CrossRef]

2. Benali-Furet, N. L., Chami, M., Houel, L., De Giorgi, F., Vernejoul, F., Lagorce, D., Buscail, L., Bartenschlager, R., Ichas, F., Rizzuto, R. and Paterlini-Bréchot, P. 2005. Hepatitis C virus core triggers apoptosis in liver cells by inducing ER stress and ER calcium depletion. Oncogene 24: 4921-4933. [Medline] [CrossRef]

3. Berridge, M. J., Lipp, P. and Bootman, M. D. 2000. The versatility and universality of calcium signalling. Nat. Rev. Mol. Cell Biol. 1: 11-21. [Medline] [CrossRef]

4. Bhullar, S. K., Shah, A. K. and Dhalla, N. S. 2019. Store-operated calcium channels: Potential target for the therapy of hypertension. Rev. Cardiovasc. Med. 20: 139-151. [Medline] [CrossRef]

5. Bonora, M., Wieckowsk, M. R., Chinopoulos, C., Kepp, O., Kroemer, G., Galluzzi, L. and Pinton, P. 2015. Molecular mechanisms of cell death: central implication of ATP synthase in mitochondrial permeability transition. Oncogene 34: 1608. [Medline] [CrossRef]

6. Braakman, I. and Bulleid, N. J. 2011. Protein folding and modification in the mammalian endoplasmic reticulum. Annu. Rev. Biochem. 80: 71-99. [Medline] [CrossRef]

7. Cao, Y., Hao, Y., Li, H., Liu, Q., Gao, F., Liu, W. and Duan, H. 2014. Role of endoplasmic reticulum stress in apoptosis of differentiated mouse podocytes induced by high glucose. Int. J. Mol. Med. 33: 809-816. [Medline] [CrossRef]

8. Casas, C. 2017. GRP78 at the Centre of the Stage in Cancer and Neuroprotection. Front. Neurosci. 11: 177. [Medline] [CrossRef]

9. Chami, M., Oulès, B. and Paterlini-Bréchot, P. 2006. Cytobiological consequences of calcium-signaling alterations induced by human viral proteins. Biochim. Biophys. Acta 1763: 1344-1362. [Medline] [CrossRef]

10. Cybulsky, A. V., Takano, T., Papillon, J., Kitzler, T. M. and Bijian, K. 2011. Endoplasmic reticulum stress in glomerular epithelial cell injury. Am. J. Physiol. Renal Physiol. 301: F496-F508. [Medline] [CrossRef]

11. Ermak, G. and Davies, K. J. A. 2002. Calcium and oxidative stress: from cell signaling to cell death. Mol. Immunol. 38: 713-721. [Medline] [CrossRef]

12. Gao, X., Jia, R., Wang, M., Zhu, D., Chen, S., Lin, M., Yin, Z., Wang, Y., Chen, X. and Cheng, A. 2014. Construction and identification of a cDNA library for use in the yeast two-hybrid system from duck embryonic fibroblast cells post-infected with duck enteritis virus. Mol. Biol. Rep. 41: 467-475. [Medline] [CrossRef]

13. Gong, J., Wang, X. Z., Wang, T., Chen, J. J., Xie, X. Y., Hu, H., Yu, F., Liu, H. L., Jiang, X. Y. and Fan, H. D. 2017. Molecular signal networks and regulating mechanisms of the unfolded protein response. J. Zhejiang Univ. Sci. B 18: 1-14. [Medline] [CrossRef]

14. Haughey, N. J. and Mattson, M. P. 2002. Calcium dysregulation and neuronal apoptosis by the HIV-1 proteins Tat and gp120. J. Acquir. Immune Defic. Syndr. 31 Suppl 2: S55-S61. [Medline] [CrossRef]

15. Haughey, N. J., Nath, A., Mattson, M. P., Slevin, J. T. and Geiger, J. D. 2001. HIV-1 Tat through phosphorylation of NMDA receptors potentiates glutamate excitotoxicity. J. Neurochem. 78: 457-467. [Medline] [CrossRef]

16. Hills, C. E., Rasheed, N. A., Rasheed, N. A., Willars, G. B. and Brunskill, N. J. 2009. C-peptide reverses TGF-beta-1 induced changes in renal proximal tubular cells: implications for treatment of DN. Am. J. Physiol. 296: 614-621.

17. Huang, T. J., Liu, S. H., Kuo, Y. C., Chen, C. W. and Chou, S. C. 2014. Antiviral activity of chemical compound isolated from Artemisia morrisonensis against hepatitis B virus in vitro. Antiviral Res. 101: 97-104. [Medline] [CrossRef]

18. Inagi, R., Nangaku, M., Onogi, H., Ueyama, H., Kitao, Y., Nakazato, K., Ogawa, S., Kurokawa, K., Couser, W. G. and Miyata, T. 2005. Involvement of endoplasmic reticulum (ER) stress in podocyte injury induced by excessive protein accumulation. Kidney Int. 68: $2639-2650$. [Medline] [CrossRef]

19. Jacolot, S., Férec, C. and Mura, C. 2008. Iron responses in hepatic, intestinal and macrophage/monocyte cell lines under different culture conditions. Blood Cells Mol. Dis. 41: 100-108. [Medline] [CrossRef]

20. Lam, K. M. and Lin, W. Q. 1986. Antibody-mediated resistance against duck enteritis virus infection. Can. J. Vet. Res. 50: 380-383. [Medline]

21. Lewy, T. G., Grabowski, J. M. and Bloom, M. E. 2017. BiP: Master Regulaton of the Unfolded protein response and crucial factor in flavivire 
biology. Yale J. Biol. Med. 90: 291-300. [Medline]

22. Li, Y., Ge, M., Ciani, L., Kuriakose, G., Westover, E. J., Dura, M., Freed, J. H., Maxfield, F. R., Lytton, J. and Tabas, I. 2004. Enrichment of endoplasmic reticulum with cholesterol inhibits sarcoplasmic-endoplasmis reticulum calcium ATPase-2b activity in parallel with increased order of membrane lipids: implications for depletion of endoplasmic reticulium calcium store and apoptosis. J. Biol. Chem. 279: 37030. [Medline] [CrossRef]

23. Liver, E. A. F. T. S. O. T. (European Association for the Study of the Liver). 2012. EASL clinical practice guidelines: Management of chronic hepatitis B virus infection. J. Hepatol. 57: 167-185. [Medline] [CrossRef]

24. Luciani, D. S., Gwiazda, K. S., Yang, T. L., Kalynyak, T. B., Bychkivska, Y., Frey, M. H. Z., Jeffrey, K. D., Sampaio, A. V., Underhill, T. M. and Johnson, J. D. 2009. Roles of IP3R and RyR Ca2+ channels in endoplasmic reticulum stress and $\beta$-cell death. Diabetes 58: 422-432. [Medline] [CrossRef]

25. Oakes, S. A. and Papa, F. R. 2015. The role of endoplasmic reticulum stress in human pathology. Annu. Rev. Pathol. 10: 173-194. [Medline] [CrossRef]

26. Paridaens, A., Laukens, D., Vandewynckel, Y. P., Coulon, S., Van Vlierberghe, H., Geerts, A. and Colle, I. 2014. Endoplasmic reticulum stress and angiogenesis: is there an interaction between them? Liver Int. 34: e10-e18. [Medline] [CrossRef]

27. Qi, X., Yang, X., Cheng, A., Wang, M., Zhu, D. and Jia, R. 2008. The pathogenesis of duck virus enteritis in experimentally infected ducks: a quantitative time-course study using TaqMan polymerase chain reaction. Avian Pathol. 37: 307-310. [Medline] [CrossRef]

28. Roberson, E. C., Tully, J. E., Guala, A. S., Reiss, J. N., Godburn, K. E., Pociask, D. A., Alcorn, J. F., Riches, D. W., Dienz, O., Janssen-Heininger, Y. M. and Anathy, V. 2012. Influenza induces endoplasmic reticulum stress, caspase-12-dependent apoptosis, and c-Jun N-terminal kinase-mediated transforming growth factor- $\beta$ release in lung epithelial cells. Am. J. Respir. Cell Mol. Biol. 46: 573-581. [Medline] [CrossRef]

29. Ruiz, M. C., Díaz, Y., Peña, F., Aristimuño, O. C., Chemello, M. E. and Michelangeli, F. 2005. Ca2+ permeability of the plasma membrane induced by rotavirus infection in cultured cells is inhibited by tunicamycin and brefeldin A. Virology 333: 54-65. [Medline] [CrossRef]

30. Saggioro, D., Silic-Benussi, M., Biasiotto, R., D'Agostino, D. M. and Ciminale, V. 2009. Control of cell death pathways by HTLV-1 proteins. Front. Biosci. 14: 3338-3351. [Medline] [CrossRef]

31. Tam, A. B., Roberts, L. S., Chandra, V., Rivera, I. G., Nomura, D. K., Forbes, D. J. and Niwa, M. 2018. The UPR activator ATF6 responds to proteotoxic and lipotoxic stress by distinct mechanisms. Dev. Cell 46: 327-343.e7. [Medline] [CrossRef]

32. Ueda, M., Daidoji, T., Du, A., Yang, C. S., Ibrahim, M. S., Ikuta, K. and Nakaya, T. 2010. Highly pathogenic H5N1 avian influenza virus induces extracellular Ca2+ influx, leading to apoptosis in avian cells. J. Virol. 84: 3068-3078. [Medline] [CrossRef]

33. Wang, G., Qu, Y., Wang, F., Hu, D., Liu, L., Li, N., Yue, R., Li, C. and Liu, S. 2013. The comprehensive diagnosis and prevention of duck plague in northwest Shandong province of China. Poult. Sci. 92: 2892-2898. [Medline] [CrossRef]

34. Wati, S., Soo, M. L., Zilm, P., Li, P., Paton, A. W., Burrell, C. J., Beard, M. and Carr, J. M. 2009. Dengue virus infection induces upregulation of GRP78, which acts to chaperone viral antigen production. J. Virol. 83: 12871-12880. [Medline] [CrossRef]

35. Wu, X., Jia, R., Zhou, J., Wang, M., Chen, S., Liu, M., Zhu, D., Zhao, X., Sun, K., Yang, Q., Wu, Y., Yin, Z., Chen, X., Wang, J. and Cheng, A. 2018. Virulent duck enteritis virus infected DEF cells generate a unique pattern of viral microRNAs and a novel set of host microRNAs. BMC Vet. Res. 14: 144. [Medline] [CrossRef]

36. Yordy, B. and Iwasaki, A. 2011. Autophagy in the control and pathogenesis of viral infection. Curr. Opin. Virol. 1: 196-203. [Medline] [CrossRef]

37. Zhu, L. P., Yu, X. D., Ling, S., Brown, R. A. and Kuo, T. H. 2000. Mitochondrial $\mathrm{Ca}^{2+}$ homeostasis in the regulation of apoptotic and necrotic cell deaths. Cell Calcium 28: 107-117. [Medline] [CrossRef] 